\title{
Educação bilíngue inclusiva para surdos como espaço de resistência $^{12}$
}

\section{Inclusive bilingual education for the deaf as a space of resistance}

Mariana Peres de Morais (i)

Vanessa Regina de Oliveira Martins (ii)

\begin{abstract}
(i) Universidade Federal de São Carlos - UFSCar, São Carlos, SP, Brasil. https://orcid.org/0000-00032254-9419, marianaperesm@gmail.com.

(ii) Universidade Federal de São Carlos - UFSCar, São Carlos, SP, Brasil. https://orcid.org/0000-00033170-293X, vanymartins@hotmail.com.
\end{abstract}

\section{Resumo:}

O presente artigo objetiva analisar as trajetórias históricas e as composições de saberes que ativaram um novo cenário educacional inclusivo bilíngue para surdos, distinto das propostas inclusivas consonantes com o modelo referendado pelas diretrizes que sustentam os discursos e as práticas na educação especial. São apresentadas propostas bilíngues para surdos e as ações que buscam romper com o paradigma que ainda mantém a centralidade educacional na língua portuguesa. Os conceitos das filosofias da diferença, em Michel Foucault, Gilles Deleuze e Félix Guattari, contribuíram para a análise e historicização (saber/poder) dos fatores que possibilitaram a emergência de projetos bilíngues como um campo de investigação possível. Nesse sentido, a relevância desta pesquisa consiste em contribuir com as discussões existentes sobre os deslocamentos de saberes para procedimentos educacionais, realizados em municípios que adotam métodos inclusivos bilíngues, a fim de demarcar a história dos movimentos sociais em direção a propostas de escolas-polo bilíngues.

Palavras-chave: educação de surdos, relações de saber e poder, resistências
\end{abstract}

\footnotetext{
1 Apoio: Fundação de Amparo à Pesquisa do Estado de São Paulo (Fapesp), processo no 2018/08930-0.

${ }^{2}$ Normalização, preparação e revisão textual: Douglas Mattos (Tikinet) - revisao@tikinet.com.br
} 


\begin{abstract}
:
This article aims to analyze the historical trajectories and knowledge compositions that have activated a new inclusive bilingual educational scenario for deaf, distinct from the inclusive proposals in line with the model supported by the guidelines that support discourses and practices in special education. Bilingual proposals for deaf are presented and actions that seek to break with the paradigm that still maintains the centrality of education in the Portuguese language. Concepts of the philosophies of difference in Michel Foucault, Gilles Deleuze and Félix Guattari contributed to the analysis and historicization (knowledge/power) of the factors that allowed the emergence of bilingual projects as a possible field of investigation. The relevance of this research is to contribute with the existing discussions about the displacements of knowledge for educational procedures, carried out in municipalities that adopt bilingual inclusive methods, in order to demarcate the history of social movements towards proposals of bilingual polo-schools.
\end{abstract}

Keywords: education for the deaf, knowledge and power relations, resistance

\title{
Introdução
}

Neste artigo apresentamos alguns dos discursos presentes nos materiais produzidos e veiculados pela comunidade surda (como ação de resistência aos modelos hegemônicos) e por órgãos públicos que retratam saberes e práticas sobre a surdez e a educação de surdos. Tais discursividades produzem sujeitos surdos que se experienciam como alunos de escolas comuns com propostas inclusivas, fundamentadas na Política de Educação Especial, uma política marcada, muitas vezes, por propostas que tomam a normalidade ouvinte como centro de produções de práticas educacionais. Problematizamos, assim, as políticas inclusivas e aquilo em que elas podem estar camuflando os discursos políticos que, articulados aos saberes científicos, produzem o "verdadeiro" saber, como uma prática social, no caso, produzindo as políticas educacionais para surdos. Tais saberes, na óptica foucaultiana, produzem-se como um regime de verdades que, por meio de prescrições normativas, solidificam e direcionam determinadas condutas (Foucault, 2006). Ao olhar alguns documentos sociais, nota-se a proliferação de discursos e saberes que engessam outros saberes e que são significativos para a reflexão e produção de práticas que mobilizam ações voltadas à educação de surdos. 


\section{pro.posıções}

http://dx.doi.org/10.1590/1980-6248-2018-0089

$e$-ISSN 1980-6248

Apresentamos neste artigo o processo de problematização em torno de ações educativas, bem como saberes que fizeram emergir concepções sobre o tipo de educação proposta e anunciada às pessoas surdas. Objetiva-se, com isso, desenvolver uma reflexão sobre os conceitos de bilinguismo para surdos, as práticas escolares atuais e os movimentos de resistência das comunidades surdas contra o "modelo geral" imposto pela política de inclusão, que centraliza a educação pela ação da língua oral: a língua portuguesa. Esses conceitos mencionados serão abordados e desenvolvidos no interior deste escrito. Faremos esse trajeto por entender que, assim como a inclusão (com as várias concepções sobre o que seja incluir) não é consenso, o modo de produzir educação bilíngue para surdos também não é.

\section{Educação bilíngue de surdos: trajetórias marcadas pelas resistências locais}

As políticas públicas avançaram consideravelmente nas últimas décadas, no sentido da democratização do acesso educacional e na busca da qualidade do ensino, especialmente na Educação Básica. No que diz respeito à pessoa surda, a trajetória do movimento político de luta e resistência contra a oralização em direção à propagação da língua de sinais é pertinente e tem sido a maior posição levantada pelas comunidades surdas. Principalmente, ao tratar sobre as discussões a respeito de qual modelo educacional seria indicado para este público.

A implementação de uma proposta educacional numa vertente bilíngue para surdos como reivindicação global originou-se com movimentos iniciados a partir da década de 1980. Para Skliar (1998), a educação bilíngue para surdos requer muito mais do que uma mudança na proposta pedagógica ou a inserção da língua de sinais sem uma política efetiva de "entrada" das questões culturais surdas no currículo escolar. O autor defende a construção de uma ideologia, num fazer surdo ${ }^{3}$, compondo uma nova arquitetura educativa. Assim, o sucesso ou fracasso dos programas educacionais das escolas bilíngues para surdos está diretamente vinculado ao tipo de serviço e política pública adotada. No Brasil, essas discussões ganharam maior visibilidade na

\footnotetext{
3 O uso do "fazer surdo" refere-se à construção de ações produzidas com o protagonismo de pessoas surdas na sua feitura. Deste modo, buscamos pensar a surdez como uma experiência produzida no corpo das pessoas surdas e, por esse motivo, suas pontuações possibilitam construir políticas pautadas na experiência e na diferença. Evidente que existem pluralidades de "desejos" surdos, mas anunciamos o "fazer surdo" como desejo de um espaço de construção coletiva de políticas públicas com a presença de sujeitos surdos em todos os processos.
} 


\section{pro.posıções}

http://dx.doi.org/10.1590/1980-6248-2018-0089

década de 1990 e, nesse período, começaram-se movimentos sociais, liderados e apoiados pelas comunidades surdas brasileiras e por pesquisadores surdos e ouvintes, que se mobilizaram para o reconhecimento da Língua Brasileira de Sinais (Libras) e a implantação da educação bilíngue para surdos em nosso país (Lodi, 2012).

Apesar de ser um tema recente, as revisões literárias brasileiras apresentam trabalhos científicos que investigam o bilinguismo de surdo e as reações aos modelos proposto nas escolas inclusivas, tendo como pauta uma educação de surdos baseado na língua de sinais como central nas práticas de ensino, ou como língua de instrução escolar (Lacerda, Santos, Lodi, Gurgel, 2016; Lopes, 2007; Müller, Sturmer, Karnopp, \& Thoma, 2013). No entanto, os caminhos para a educação bilíngue de surdos ainda é um assunto polêmico, visto que a própria legislação brasileira, através do Decreto $n^{\circ} 7.611 / 2011$, defende a existência de um sistema educacional inclusivo em todos os níveis, sem discriminação e com base na igualdade de oportunidades. Ressaltamos que, assim como a língua de sinais sofreu períodos de proibição quanto ao seu uso, a defesa de escolas especializadas no atendimento às pessoas surdas também travou e continua travando lutas pela sua manutenção e pela qualidade e modo de efetivação do "fazer" a educação de surdos em direção à inserção da diferença linguística. Têm sido constantes as discussões da real necessidade de políticas locais (municipais, que sejam por meio de movimentos militantes) assumirem formas de instrumentos de luta das minorias, com o intuito de encontrar brechas para atuar de forma revolucionária, em oposição aos macropoderes estatais, na intenção de um sistema favorável às diferenças linguísticas e culturais.

Ao traçar tais discussões, não se pretende aqui exercitar a defesa de um modelo único de escola que deva acolher todos os surdos, tampouco apenas empreender uma crítica e/ou apontar falhas nos processos educacionais para esse público. Pretendemos, através da análise de alguns documentos oficiais, compreender como se têm dado os impasses nas questões relativas à educação dos surdos no Brasil e, com isso, dar "voz", no sentido de fazer falar e potencializar a reflexão, aos movimentos surdos e manifestos que contestam outras ações para além das produzidas como modo único de desenvolvimento educacional e inclusivo.

Prosseguindo com o tema, a comunidade surda, em conjunto com os educadores e pesquisadores (Campello \& Rezende, 2014; Lacerda, 2006; Lodi, 2013; Martins, 2016), tem reivindicado a educação bilíngue de crianças surdas, a saber, uma educação que toma a língua de sinais como constitutiva da aprendizagem. O processo de desenvolvimento linguístico 


\section{pro.posições}

$e$-ISSN 1980-6248

http://dx.doi.org/10.1590/1980-6248-2018-0089

almejado é tal qual o das crianças ouvintes, só que adquirindo a língua de sinais como primeira língua, ou língua matriz, e o português como sua segunda língua, ou língua adicional. As experiências em alguns munícipios, tal como a apresentada por Lacerda, Santos \& Martins (2016), apontam que a proposta bilíngue em escolas inclusivas tem sido produzida com mudanças curriculares e com a parceria de pesquisadores surdos para a reorganização do que seja uma escola bilíngue (Libras/Português), em busca de uma ação efetiva da entrada da língua de sinais no interior escolar. As práticas educacionais bilíngues como essa utilizam a Libras como língua de instrução, a qual dará todo o suporte linguístico para que o aluno surdo tenha acesso aos conteúdos curriculares (Lacerda, Santos, \& Martins, 2016).

Fernandes \& Moreira (2009) salientam que os surdos podem ser considerados bilíngues ao fazer uso e serem constituídos por duas línguas legitimamente brasileiras, posto que ambas expressam valores, crenças e modos de percepção da realidade de pessoas que compartilham elementos culturais comuns. Atentando para as afirmativas dos autores, pode-se pontuar que o fundamento do bilinguismo pretende proporcionar um ambiente linguístico em que a comunicação, através da língua de sinais e do português escrito, seja aprendida de maneira espontânea como acontece na aquisição de uma língua oral, favorecida em situações de aprendizagem em todos os meios: na família, na escola, ou seja, em todos os lugares e a todo o momento. Por isso, é pertinente introduzir a criança surda em um contexto de aprendizado de duas línguas em ambientes em que haja significação para ela, a fim de que ela possa constituir-se como sujeito linguístico, da mesma maneira como essa oportunidade é oferecida à criança ouvinte (Slomski, 2012). Nessa perspectiva, as denúncias feitas pelas comunidades surdas e por ouvintes integrantes das causas em prol da escolarização de surdos têm demonstrado transformações e alcançado mudanças nesse cenário. Em 2010 houve uma grande mobilização pelos movimentos surdos brasileiros, após a Conferência Nacional da Educação, em que foram defendidas algumas propostas que serviriam de base para a elaboração do Plano Nacional de Educação (PNE).

Os líderes surdos apresentaram recomendações para a manutenção e criação de novas escolas bilíngues para surdos que seguissem algumas garantias, tais como:

- garantir às famílias e aos surdos o direito de optar pela modalidade de ensino, garantindo o acesso à educação bilíngue;

- garantir o contato dos alunos surdos com professores surdos, oportunizando sua identificação linguística e cultural; 


\section{pro.posições}

http://dx.doi.org/10.1590/1980-6248-2018-0089

\section{$e$-ISSN 1980-6248}

- incentivar e apoiar financeiramente a criação do curso de graduação em Pedagogia Bilíngue (Mourão, 2011, p. 11).

Porém, naquele momento, a comunidade surda não se sentiu atendida democraticamente. Segundo Mourão (2011), no final da plenária, um grupo do Ministério da Educação (MEC) chamou os representantes das minorias à parte, em lugar fechado, para que votassem contra as propostas de educação de surdos, as quais não tinham sido totalmente aceitas e foram acusadas de ideias segregacionistas. Portanto, os conceitos favoráveis às escolas comuns que adotam a ideia de inclusão, como presença da diferença (ou dos corpos diferentes) dentro de espaços únicos comuns, tiveram maior repercussão e "voz" no evento (Mourão, 2011).

Tendo em vista que o termo inclusão escolar, em um de seus usos, está associado a "uma prática de colocação de alunos com dificuldades nas classes comuns, ... englobando também a noção de inserção de apoios, serviços e suportes nas escolas regulares" (Mendes, 2006, p. 402), a Direção de Políticas Educacionais Especiais do MEC afirmou, através de registros colhidos no número 41 da Revista da Feneis (2010), a justificativa de que havia princípios da educação inclusiva para serem seguidos, e que aderir às propostas de manutenção e abertura de escolas de surdos seria ir contra esses princípios. Com isso, o MEC alegou ter agido em defesa das políticas educacionais vigentes e das orientações do governo em não aceitar tais propostas: escolas de surdos como espaço possível de ensino. Para pensar nestes eventos e em sua repercussão, traremos conceitos foucaultianos para mobilizar algumas reflexões. Conforme Foucault $(2006,2011)$, sobre as produções de verdades sociais, nem todos os sujeitos estão autorizados a fazer circular determinadas discursividades e produzir, com elas, formas de condução das vidas (da população). Há proibições na sociedade no que diz respeito às verdades de um discurso, assim como existem "sujeitos autorizados" para falar sobre determinados assuntos. Em relação à educação dos surdos, as "pessoas autorizadas" a dizer "verdades", naquele momento, não foram os próprios surdos, mas outros sujeitos presentes e representantes, no caso supramencionado, do MEC - em sua maioria ouvintes, longe de sentirem efetivamente a experiência e marcas da surdez em seus corpos.

Nesse contexto de condução das condutas das vidas surdas ${ }^{4}$, em 2011, a Diretoria de Políticas Educacionais Especiais comunicou oficialmente ao diretor do Instituto Nacional de

\footnotetext{
${ }^{4}$ Usamos o conceito "vidas surdas" como sujeitos que se constituem visualmente e que trazem em seus corpos marcas plurais e significações múltiplas de ser e se fazer surdo. Como mencionado em nota anterior, não há uma única forma cultural de ser surdo, por isso, pluralizamos as formas de vidas surdas.
} 


\section{pro.posıções}

http://dx.doi.org/10.1590/1980-6248-2018-0089

\section{$e$-ISSN 1980-6248}

Educação de Surdos (Ines) que a escola seria fechada e os alunos matriculados seriam remanejados para escolas comuns. Essa declaração causou alvoroço na comunidade surda de todo país, provocando mobilizações, passeatas em Brasília, vídeos compartilhados em redes sociais, abaixo-assinados, matérias em jornais e debates de pesquisadores da área da surdez discutindo qual o melhor caminho para a educação dos surdos (Campello \& Rezende, 2014). Em meio a esses acontecimentos, o Decreto n ${ }^{\circ} 6.949 / 2009$, com base nos dispositivos legais da Convenção sobre Direitos das Pessoas com Deficiência, promulgada no Brasil com status de Emenda Constitucional por esse mesmo decreto (fundamentado no Decreto Legislativo $n^{\circ} 186$, de 9 de julho de 2008, conforme o que prevê o $\int 3^{\circ}$ do art. $5^{\circ}$ da Constituição Federal), diz que "as pessoas com deficiência farão jus, em igualdade de oportunidades com as demais pessoas, a que sua identidade cultural e linguística específica seja reconhecida e apoiada, incluindo as línguas de sinais e a cultura surda" (art. 30, \4). Desse modo, e tendo em vista as determinações da comunidade surda, com manifestações de resistências apresentadas contra o MEC, foi necessário que o órgão se posicionasse fazendo uma alteração na proposta inicial, retratando a declaração de que poderia fechar o Ines, sediado no Rio de janeiro. Com o movimento, além da retratação manifesta, houve aceno do MEC quanto ao apoio em iniciativas de ações a favor de programas bilíngues institucionais na direção de políticas educacionais voltadas ao ensino inclusivo de surdos.

Recorrendo novamente aos constructos de Foucault (2012), autor de referência teórica para nossa conversa, as resistências são movimentos contrários à ação de imposição de uma verdade unitária. São movimentos de contra-ações que visam à emergência de vozes locais, das vozes das pessoas por vezes politicamente silenciadas. As resistências se colocam como ação de insurreição dos saberes das pessoas que foram, por determinadas razões, desqualificadas. Assim, a contra-ação, ou a ação da resistência, "trata-se de ativar saberes locais, descontínuos, desqualificados, não legitimados", ação que promove o rompimento da "instância teórica unitária que pretenderia depurá-los" (Foucault, 2012, p. 171). No caso dos surdos, as resistências atuam como "força contra o poder ouvinte de ideologia dominante ouvintista" (Perlin, 1998, p. 69), contra as representações homogeneizantes das pessoas surdas. Atribui-se à resistência a relação ou a ação feita pelos movimentos surdos contrariando a ação "universalizante" da perspectiva inclusiva (a mais radical) como prática geral e afirmativa para toda população e público-alvo da educação especial com base na instrução pela língua oral, deixando à margem a língua de sinais. 


\section{pro.posıções}

http://dx.doi.org/10.1590/1980-6248-2018-0089

$e$-ISSN 1980-6248

Desse modo, as resistências ativadas pelos surdos, efeito das relações de poder, como oposição a um tipo de saber soberano, obtiveram resultados através dos movimentos de luta contrários às exigências da perspectiva ouvinte impostas à comunidade surda. A isso exemplificamos a liberação da Portaria n ${ }^{\circ} 1.060$, de 30 de outubro de 2013, que institui a criação de um grupo de trabalho no MEC, com o objetivo de elaborar subsídios para a Política Nacional de Educação Bilíngue e orientações para a formação inicial e continuada de professores para o ensino da Libras, e da língua portuguesa como segunda língua.

Foi enfatizado neste grupo de trabalho (GT) que a Federação Nacional de Educação e Integração dos Surdos (Feneis) seria a representante para recomendações de políticas linguísticas, para traçar metas e desvincular a educação linguística de surdos da educação especial por perceberem que havia imposições de uma política de educação inclusiva inconstante, e por não ver sentido em que os surdos sejam

alocados e programados pela Diretoria de Políticas da Educação Especial, pois esse historicismo tem rendido à nossa educação a imposição de uma política de educação inclusiva que ora aloca os alunos surdos em escolas comuns com Atendimento Educacional Especializado (AEE), entendido como oferta educacional esporádica e fragmentada, no contraturno da aula, realizada durante poucas horas por semana (Campello \& Rezende, 2014, p. 88) ${ }^{5}$.

Essas imposições têm impelido a escola comum, com atendimento especializado no contraturno, a não considerar as reais necessidades de desenvolvimento de linguagem em Libras de alunos surdos, de modo mais natural ${ }^{6}$, como língua matriz. Nesse caso, acontece o que se pode chamar de "burocratização" da língua de sinais, já que ela é determinada para uso e aprendizado em momentos específicos. Para a comunidade surda, "O AEE jamais será um ambiente linguístico natural", pois a língua de sinais fica banida "a um local e a um aprendizado complementar ou suplementar, mas não principal, como a legislação ordena” (Feneis, 2011, s. p.). Não se viabiliza a interação em uso cotidiano da língua, o que dificulta sua aquisição tal qual nos processos que ocorrem com falantes de línguas orais.

\footnotetext{
${ }^{5}$ Destacamos que as duas pesquisadoras são surdas e cientificamente vêm reivindicando o acento de propostas bilíngues inclusivas para surdos de modo a narrar as experiências como forma de potencializar as diferenças linguísticas na construção de políticas educacionais.

${ }^{6}$ Aqui o uso do "natural" se faz em consonância com os conceitos trazidos da área da linguística, em contraposição ao ensino e uso de uma linguagem artificial.
} 


\section{pro.posıções}

$e$-ISSN 1980-6248

http://dx.doi.org/10.1590/1980-6248-2018-0089

Nessa perspectiva, em 2011, a Feneis elaborou um documento para a abertura da Convenção Internacional das Pessoas com Deficiência ${ }^{7}$, justificando que as crianças surdas precisam ser incluídas primeiramente através da língua de sinais e de práticas culturais mais apropriadas antes de serem incluídas nas diferentes áreas da vida escolar, que se dará em estágios posteriores.

As mobilizações a favor das ideias da educação bilíngue avançaram e, com isso, a Câmara dos Deputados aceitou a inclusão das escolas bilíngues para surdos nas metas do PNE. Portanto, em 2014, a proposta foi aprovada e sancionada com a Lei $n^{\circ} 13.005 / 2014$, que aprovou este plano, em que se dispõe na estratégia a meta descrita na alínea 4.7 , objetivando

garantir a oferta de educação bilíngue, em Língua Brasileira de Sinais - LIBRAS como primeira língua e na modalidade escrita da Língua Portuguesa como segunda língua, aos (às) alunos (as) surdos e com deficiência auditiva de 0 (zero) a 17 (dezessete) anos, em escolas e classes bilíngues e em escolas inclusivas, nos termos do art. 22 do Decreto $N^{\circ} 5.626$, de 22 de Dezembro de 2005, e dos arts. 24 e 30 da Convenção sobre os Direitos das Pessoas com Deficiência, bem como a adoção do Sistema Braille de leitura para cegos e surdo-cegos ("Plano Nacional", 2014, p. 56, grifo nosso).

Veja que no PNE a ação das escolas bilíngues aparece distinta da ação da escola inclusiva. Nota-se que, diante dessa construção discursiva, há saberes que efetivam um tipo de prática. São estas práticas que geram contra-ações e disputas para a manutenção de um modelo único. A proposta tem o intuito de considerar o bilinguismo como mais uma modalidade de ensino e assegurar o direito de os surdos optarem por uma das três modalidades de escolarização, aquela com que se sentirem mais confortáveis. Por conseguinte, as metas e estratégias do PNE concordam com a nota de esclarecimento da Feneis, expedida em 2013, em que há a opção de três espaços educacionais adequados para o ensino de surdos:

- Escolas bilíngues (onde a língua de instrução é a Libras, e a Língua Portuguesa é ensinada como segunda língua, mediada pela língua de instrução, Libras; essas escolas se instalam em espaços arquitetônicos próprios e nelas devem atuar professores bilíngues, sem mediação por intérpretes e sem a utilização do português sinalizado. Os alunos não precisam estudar no contraturno em classes de Atendimento Educacional Especializado, dado que a forma de ensino é adequada e não demanda atendimento compensatório);

\footnotetext{
${ }^{7}$ A Convenção Internacional das Pessoas com Deficiência abordou, além de outras propostas, a defesa das escolas bilíngues para surdos, tendo a Feneis como entidade representativa dos surdos em âmbito nacional e internacional, afiliada à International Disability Alliance, órgão que implementa a promoção e o cumprimento dos direitos das pessoas com deficiência dentro do sistema das Nações Unidas.
} 


\section{pro.posições}

$e$-ISSN 1980-6248

http://dx.doi.org/10.1590/1980-6248-2018-0089

- as classes bilíngues (que podem ocorrer nos municípios em que a quantidade de surdos não justificar a criação de uma escola bilíngue específica para surdos) podem existir na mesma edificação de uma escola inclusiva;

- nas escolas inclusivas, onde o português oral é a língua de instrução, algumas vezes mediada por intérpretes, o aluno surdo tem que estudar dois períodos, participando do Atendimento Educacional Especializado (AEE) no contraturno e são matriculados duas vezes (dupla matrícula) (Feneis, 2013, s. p.).

Através dessas modalidades anunciadas no documento da Feneis (2013), há marcada reivindicação contra a proposta de ensino de surdos comum oferecida na prática inclusiva. Essa ação contrária desvincula a concepção e o fazer sobre o ensino de surdos da prática até então ofertada pela educação especial - como uma modalidade de ensino complementar à ação comum de ensino no interior das escolas inclusivas. Essa contraposição se dá na defesa de salas com instrução em Libras, nas quais se tenha predominantemente crianças surdas ou alunos que tenham o ensino feito nesta língua, e não em salas de apoio (multifuncionais) que complementam a sala comum com ensino feito na língua portuguesa - como língua de instrução. Assim, com tais movimentos e ideais defendidos pela comunidade surda, há a conquista e o alcance, em termos legais, dos princípios de uma educação bilíngue para surdos, baseada em outros pontos, diferentes dos pontos em pauta postos nas políticas da educação especial. Esse segundo parece considerar majoritariamente a inclusão do sujeito surdo sem a defesa da língua de sinais e sua centralidade na escola, tal qual feita pelos movimentos surdos. $\mathrm{Na}$ política posta nos documentos agenciados pela educação especial, se mantém o ensino inclusivo de surdos vinculado à ação de salas multifuncionais e professor generalista de educação especial como apoio aos docentes regentes. Sendo assim, a educação bilíngue para surdos pode acontecer, pelo menos em termos legais, em diferentes espaços educacionais. Entendemos que esses modelos de espaços educacionais para o desenvolvimento do bilinguismo merecem reflexão quanto à efetividade do conceito "bilíngue", uma vez que, para acontecer de fato o ensino e a vivência de duas línguas em um mesmo ambiente escolar, não se pode reduzi-los apenas ao uso de modo instrumental da língua de sinais. Não é porque se utiliza a Libras como uma ferramenta para o ensino e a aprendizagem de surdos, inseridos na escola comum, que se pode considerar a escola de ensino como sendo um espaço efetivamente e politicamente bilíngue (Lodi, 2013).

Sobre a perspectiva bilíngue, vale ressaltar que por muitas décadas vem-se tentando apagar o plurilinguismo no Brasil, com a propagação da ideia equivocada de aqui haver uma 


\section{pro.posições}

http://dx.doi.org/10.1590/1980-6248-2018-0089

única língua, de sermos um país monolíngue. Sobre o assunto, Gonçalves \& Andrade (2007) argumentam que desenvolver a competência plurilíngue é valorizar a construção da identidade através do contato com outras línguas e culturas pela promoção de uma educação para a cidadania com vias de abertura e respeito pela diferença. Isso indica a necessidade de valorização das diferenças e das identidades plurais surdas, com respeito em seu contexto real de produção, em espaços propícios para o seu desenvolvimento. Enquanto não houver respeito pelas diferenças no cotidiano escolar e fora dele, as convicções impostas por uma sociedade plurilíngue e acessível encontrarão dificuldades para serem construídas.

Os surdos, numa perspectiva social e para as comunidades surdas, são considerados falantes de uma minoria linguística em relação às línguas oficiais orais. Não devido à imigração ou à etnia, já que a maioria nasce de famílias que falam a língua oficial da comunidade maior, à qual também pertencem por etnia; eles são minoria linguística em relação à maioria falante de línguas orais, na questão do desprestígio que as línguas de modalidade visuogestual recebem e, ainda, por se organizarem em associações em que o fator principal de agregação é a utilização de uma língua comum, a de sinais, por todos os associados (Lacerda, 2006; Lodi, 2013). Seguindo a construção textual, a minoria linguística pratica ação de resistência à língua já estabelecida oficialmente (no caso, a língua portuguesa), subsistindo como língua menor (uma língua que reivindica aparição e fratura a lógica das línguas maiores) em contraposição ao modelo constituído, a fim de expressar a comunicação por meio de um sistema de códigos sem apagar o modelo já estabelecido. Para a proliferação de espaços plurilíngues, seria necessário haver uma heterotopia linguística, a fim de permitir viver, com autonomia, as outras línguas existentes no nosso país.

Há, igualmente, e isso provavelmente em qualquer cultura, em qualquer civilização, lugares reais, lugares efetivos, lugares que são delineados na própria instituição da sociedade, e que são espécies de contra posicionamentos, espécies de utopias efetivamente realizadas nas quais os posicionamentos reais, todos os outros posicionamentos reais que se podem encontrar no interior da cultura estão ao mesmo tempo representados, contestados e invertidos, espécies de lugares que estão fora de todos os lugares, embora eles sejam efetivamente localizáveis. Esses lugares, por serem absolutamente diferentes de todos os posicionamentos que eles refletem e dos quais eles falam, eu os chamarei, em oposição às utopias, de heterotopias (Foucault, 2003, p. 415).

Para Foucault (2003), a militância produz heterotopias, lugares reais, mas que estão fora dos lugares aceitos, dos lugares impostos pela norma, são lugares que refletem lutas. Nesses espaços, existem tensões exercidas pelas relações de poder e pelas verdades que se configuram 


\section{pro.posıções}

http://dx.doi.org/10.1590/1980-6248-2018-0089

$e$-ISSN 1980-6248

como aceitas pela sociedade. Destarte, temos a língua como algo concreto, usada no cotidiano das pessoas de diversas maneiras, a qual se transforma de acordo com o lugar em que está inserida e se altera seguindo o contexto e as modificações da sociedade a que ela pertence. Portanto, a língua não é "um bloco compacto, homogêneo, parado no tempo e no espaço, mas sim um universo complexo, rico, dinâmico e heterogênico" (Bagno, 2008, p. 136). À vista disso, a língua constitui-se como algo que se movimenta entre lugares e entre sujeitos, estando sempre em processo e não como algo pronto e acabado: a língua é viva e é vida.

No contexto da língua de sinais, foi e continua sendo um desafio a aceitação do ensino pautado na utilização de duas línguas, porque há o posicionamento de mando da língua portuguesa como língua de interface social e cultural no Brasil, isso posto pelo ideário monolíngue já apresentado. No campo da educação e da política linguística, enfrenta-se a validação e o incentivo de os surdos serem educados em ambientes escolares em que haja a coexistência de dois sistemas linguísticos diferentes. Tais aspectos revelam as lutas para ações e práticas educacionais e políticas que implementem o bilinguismo de surdos nas escolas comuns e rompam o essencialismo linguístico da língua portuguesa como língua de instrução e de mando (Lodi, 2013).

Entre as lutas apontadas pelos movimentos surdos, a que mais se destaca é, portanto, a defesa de escolas bilíngues, como foi explanado nas ideias anteriores, a qual é uma proposta construída em defesa do direito de as escolas bilíngues para surdos existirem como escola e não apenas no espaço do AEE - para que, assim, "os aspectos específicos da educação dos surdos, sua forma peculiar de significação de mundo e o ensino sistematizado da Libras como disciplina sejam garantidos a todos" (Lacerda, Santos, \& Martins, 2016, p. 15). Tais ações de espaços bilíngues foram sendo produzidas por meio de projetos e programas bilíngues que modificaram as formas de condução da chamada escola inclusiva. Dois programas serão aqui analisados, os quais foram nomeados por projetos de escola-polo inclusiva bilíngue de surdos, configurandose por uma estrutura em que agregam um número significativo de surdos na unidade escolar e profissionais qualificados para a promoção do programa educacional bilíngue, tais como: professores bilíngues surdos e ouvintes, intérpretes educacionais apenas do Ensino Fundamental II em diante, instrutores surdos, entre outros profissionais. Além da equipe mencionada, ressalta-se que estas propostas trouxeram de novidade as salas bilíngues multisseriadas de surdos na Educação Infantil, nos anos iniciais do Ensino Fundamental I e nas aulas de língua portuguesa do Ensino Fundamental II. Tais ações modificaram também a 


\section{pro.posições}

http://dx.doi.org/10.1590/1980-6248-2018-0089

estrutura física e a organização curricular, pois propõem a docência bilíngue e a instrução pela Libras (Lacerda, Santos, \& Martins, 2016). É com a análise dos acontecimentos que propiciaram as ações e aparições destas experiências de escolas-polo que o artigo caminhará.

\section{Escolas-polo inclusivas bilíngues: resistência ao sistema inclusivo comum}

Conforme apontado anteriormente, a partir de 1996, a partir da Lei de Diretrizes e Bases da Educação Nacional, Lei no 93.394/1996, registram-se avanços quando se prevê acesso à educação para crianças com deficiências nas escolas de ensino comum. A partir disso, o Decreto n 3.298/1999 dispõe que os órgãos e entidades responsáveis pela educação pública devem oferecer, se necessário, serviços de acessibilidade para alunos com necessidades especiais. A partir de então, a educação especial decorreu como forma de apoio especializado para atender às peculiaridades da pessoa com deficiência. Contudo, "embora houvesse a oferta de atendimentos da educação especial e das escolas especiais de surdos, não havia garantia de respeito ao direito linguístico do aluno surdo” (Lacerda, Albres, \& Drago, 2013, p. 69).

Cabe destacar que durante esse período, com a comunidade surda reivindicando seus direitos, travaram-se lutas por espaço de aparição da língua de sinais, e tornou-se cada vez mais natural que as pessoas surdas buscassem por qualificação acadêmica, apresentando interesse de ingressar no Ensino Superior. A partir dessa necessidade, o MEC liberou a Portaria $\mathrm{n}^{\mathrm{o}}$ 1.679/1999, atestando o compromisso formal das instituições educacionais de Ensino Superior de proporcionar intérpretes de Libras, além de outros recursos necessários ${ }^{8}$ para o aprendizado de alunos surdos em curso superior. Foi mais um avanço conquistado pelos movimentos surdos, porém, este compromisso que consta da Portaria não necessariamente foi aplicado na prática de maneira geral.

Seguindo esse caminho de garantia dos direitos dos surdos, tanto em relação ao acesso à sua língua e à educação, os líderes da comunidade surda, articulando-se com pesquisadores da área, procuraram interferir nas políticas educacionais comprometidas com a educação, reivindicando leis que realmente priorizassem suas reais necessidades, pois apesar de a legislação

\footnotetext{
8 Ressaltamos que o uso da palavra "recurso" para apontar a ação do intérprete educacional está registrado no documento legal descrito, não sendo, no entanto, visto deste modo "instrumental" pelas autoras deste texto.
} 


\section{pro.posıções}

$e$-ISSN 1980-6248

http://dx.doi.org/10.1590/1980-6248-2018-0089

brasileira ter cedido a algumas requisições dos surdos, muitos de seus direitos ainda não são devidamente respeitados. Entre as lutas previstas pelos movimentos surdos, como explanado no tópico anterior, a que mais se destaca é a defesa por escolas bilíngues, o que quer dizer que os surdos reivindicam o ensino bilíngue no turno, e não no contraturno, como mais comumente ofertado.

Ora, se existem documentos, como a Lei no $10.436 / 2002$, que reconhece a língua de sinais como meio de comunicação e expressão das comunidades surdas, e o Decreto $n^{\circ} 5.626 / 2005$, que regulamenta a lei anterior e ainda garante que a educação de surdos se dê em língua de sinais, então por que não se exigir esse direito?

As mobilizações propostas pelos surdos não aparecem como uma simples relutância, apenas pelo fato de resistir aos moldes idealizados das classes majoritárias. Mais do que isso, evidenciam as possibilidades de modificações do padrão político proposto, ou melhor, imposto, envolvendo de maneira coletiva ao emergir como força contrária, promovendo fissuras por incomodar, com ações que caminham na contramão das forças vigentes.

Por essa razão, a comunidade surda, ativistas surdos, seus familiares, profissionais e pesquisadores da área da surdez (ouvintes e surdos), também insatisfeitos com a realidade da inclusão, realizaram atividades em todos os estados do Brasil, através de palestras, apresentações teatrais, passeatas, audiências públicas, exposições etc., mais fortemente durante o nono mês do ano ${ }^{9}$, buscando mobilizar as autoridades e a sociedade para garantir seus direitos humanos, linguísticos e culturais, assim como "construir coletivamente reflexão e conhecimentos sobre a política educacional para surdos e a necessidade de uma aplicação efetiva de educação de qualidade para esses sujeitos, desde a Educação Básica até a Universidade” (Silva, Fernandes, \& Rocha, 2016, p.63).

\footnotetext{
9 "Setembro Azul" é uma das principais ações organizada pela comunidade surda em âmbito nacional. Muitas vezes acontece em forma de eventos realizados em parceria com universidades e associações de surdos. Um de seus objetivos é favorecer o diálogo entre pesquisadores e líderes surdos com a comunidade ouvinte. O mês de setembro é mundialmente comemorativo, pois é repleto de datas significativas que refletem a história de lutas e conquistas da comunidade surda, como o Dia Internacional do Surdo e o Dia do Tradutor. As principais reivindicações do Movimento Surdo no Setembro Azul são pleiteadas em: acessibilidade de comunicação e informação, principalmente em órgãos, locais e serviços públicos; respeito, divulgação e valorização das Libras e da cultura surda, entre outras reivindicações.
} 


\section{pro.posıções}

http://dx.doi.org/10.1590/1980-6248-2018-0089

Através dessas ações menores, ações que buscam os escapes, as fugas, é que foi proposto $^{10}$, em 2003, um projeto de escolarização para as pessoas surdas. Inicialmente, em duas escolas do município de Piracicaba, cinco no município de Campinas (duas de Ensino Infantil, duas do Ensino Fundamental e uma de Educação de Jovens e Adultos - EJA, a última mantida até os dias atuais), atuando através de um convênio Universidade/Prefeitura Municipal em parceria com a Secretaria Municipal de Educação/Educação Especial e, ainda, duas unidades escolares (Ensino Infantil e Fundamental), em funcionamento atualmente, no município de São Carlos. Essas escolas em São Carlos tornaram-se referência para crianças surdas na rede municipal de ensino, sendo uma escola de Educação Infantil e uma de Ensino Fundamental.

Portanto, passou-se a prever uma construção educacional no formato inclusivo e bilíngue, com a função de atender às reais necessidades do alunado surdo, a fim de garantir sua entrada e permanência. Para o desenvolvimento desta proposta educacional, fez-se necessária uma equipe de profissionais formada por

a) 06 intérpretes de Libras/Português responsáveis por propiciar o acesso dos alunos surdos aos conteúdos ministrados; b) 02 educadores surdos responsáveis pelo ensino de Libras para os profissionais da escola e pelo desenvolvimento linguístico dos alunos surdos em Libras; c) 02 auxiliares de pesquisa que atuam na organização e implementação das propostas visando uma boa articulação entre a equipe escolar e a universitária e d) 01 pedagoga especialista em educação de surdos responsável pelo desenvolvimento de oficinas de português para as crianças surdas que estão no ensino fundamental (primeira etapa) (Lacerda \& Lodi, 2007, p. 2).

Buscou-se, assim, uma configuração outra de estrutura pedagógica para os surdos na escola comum, embora tenha sido apresentado com efeito de certa resistência aos espaços existentes até então ofertados conforme a Declaração de Salamanca (1994), orientados pela política educacional nacional. Portanto, tal proposta inclusiva bilíngue teve que ser adequada às salas regulares de ensino.

Sendo assim, as crianças surdas matriculadas na Educação Infantil, numa primeira proposta de construção deste espaço bilíngue, permaneciam incluídas nas salas de aulas comuns e eram acompanhadas por um intérprete de Libras. No contraturno, participavam de aulas de

\footnotetext{
10 A proposta de escolarização das pessoas surdas na perspectiva bilíngue se deu pela Prof. ${ }^{a}$ Dr. ${ }^{a}$ Cristina Lacerda e Ana Lodi, de 2003 a 2007, em duas escolas municipais (escolas-polo) de Piracicaba através de uma parceria entre a Universidade Metodista de Piracicaba (Unimep) e a Prefeitura Municipal, financiada pelo Fundo de Apoio à Pesquisa da Unimep, pelo Conselho Nacional de Desenvolvimento Científico e Tecnológico (CNPq) e pela Fundação de Amparo à Pesquisa do Estado de São Paulo (Fapesp), a fim de prever uma representação educacional inclusiva e bilíngue para surdos.
} 


\section{pro.posıções}

http://dx.doi.org/10.1590/1980-6248-2018-0089

Libras, ministradas pelos educadores surdos, a fim de propiciar o desenvolvimento de linguagem das crianças, considerando-se que a maioria chega à escola sem ter tido contato anterior com a Libras ou com experiências restritas nesta língua em seu ambiente familiar e social. Além disso, o programa ofereceu suporte de capacitação aos professores, funcionários e intérpretes de Libras com curso de formação continuada, planejamento de atividades e reuniões periódicas sobre metodologias e estratégias de ensino-aprendizagem (Lodi \& Lacerda, 2009).

Graças a esse novo dispositivo emergente de estratégias, práticas e técnicas em resistência à educação majoritária, realizadas pelas pesquisadoras e sua equipe de profissionais e apoiadas pelos profissionais da escola, possibilitou-se a contribuição para deslocar um saber, já constituído até então, para um saber outro enquadrado em uma nova conjuntura, traçando, assim, a proposta de uma escola que seja caracterizada também para o público surdo. Consideramos, nesse contexto, o termo "emergência" como "um salto pelo qual passa dos bastidores para o teatro, ... a emergência designa um lugar de afrontamento. ... Ninguém é, portanto, responsável por uma emergência; ninguém pode se autoglorificar por ela; ela sempre se produz no interstício" (Foucault, 2012, p. 67).

Desse modo, pode-se dizer que os aspectos manifestados por essa nova proposta de educação para surdos emergiram dos bastidores (universidade) para o palco do teatro (ambiente escolar) como um ponto de surgimento, de aparecimento, em que se produz sempre determinado estado de força, fazendo saltar vozes outras sufocadas para o surgimento de novas ações. Diante da observação da implantação das escolas-polo, após a primeira experiência e com aprendizados dela, em outros dois munícipios do interior do estado de São Paulo, notou-se que nos projetos de escola-polo foram propostos um novo modelo distinto do descrito anteriormente, com a abertura de salas de instrução em Libras na Educação Infantil e no ensino Fundamental I, baseado na justificativa do desenvolvimento linguístico das crianças e a dificuldade de ensino realizado por processo tradutório, ou seja, com intérpretes educacionais, advindos de experiências anteriores (Morais, 2018).

Este novo programa ${ }^{11}$, com salas bilíngues e estrutura diferenciada, se propôs a desenvolver em conjunto com uma escola municipal do interior do estado de São Paulo, de

\footnotetext{
${ }^{11}$ O programa de inclusão bilíngue para surdos analisado neste texto opera através de projeto de extensão e pesquisa vinculado à Universidade Federal de São Carlos. Inicialmente, o projeto foi realizado em duas cidades do estado de São Paulo: Piracicaba e Campinas. Atualmente, o projeto também está em vigor na cidade de São Carlos, o qual foi implantado desde o ano de 2011. São projetos/programas que demonstram a necessidade de se pensar de modo macro em políticas educacionais efetivas, que marquem o caráter bilíngue do ensino de surdos.
} 


\section{pro.posıções}

http://dx.doi.org/10.1590/1980-6248-2018-0089

Educação Infantil, Ensino Fundamental e EJA, uma experiência de inclusão de alunos surdos incorporando a Libras ao espaço escolar, repensando metodologias e desenvolvendo didáticas apropriadas para estes alunos. Para tal desenvolvimento, foram oferecidas

1) formação continuada, a toda a equipe que atuante na escola, sobre a surdez e sobre a Libras, abordando-se a constituição da língua e as particularidades de seus processos discursivosenunciativos; 2) formação continuada sobre didática e estratégias de ensino para alunos surdos para professores ouvintes, instrutores surdos e intérpretes de Libras. Para tal, além das ações dos pesquisadores nas escolas, havia a presença também de: a) intérpretes de Libras/Português que propiciaram o acesso aos alunos surdos dos conteúdos ministrados na segunda etapa do ensino Fundamental e EJA; b) de instrutores surdos responsáveis pelo ensino de Libras para os profissionais das escolas e pelo desenvolvimento linguístico dos alunos surdos em Libras; c) Professores Bilíngues responsáveis pelas salas de aula com língua de instrução Libras na Educação Infantil e Ensino Fundamental I (Lodi \& Lacerda, 2009, p. 25).

Como visto acima, a execução das atividades da Educação Infantil acontecia em salas multisseriadas conduzidas por uma professora bilíngue ouvinte e, em algumas oportunidades, uma instrutora surda, respeitando a representação linguística para a aquisição de Libras, nos primeiros anos do projeto. Posteriormente, o projeto sofreu mudanças em seu caminho pela proveniência de um discurso de poder estabelecido pela força da nova gestão da Secretaria de Educação do Município, a qual obrigou o projeto inclusivo bilíngue às práticas corretivas e disciplinares, ao considerar que as crianças surdas não deveriam estar em salas multisseriadas e, sim, em salas comuns com a maioria das crianças ouvintes, em que o português era a língua predominante e com uma professora regente ouvinte, sem fluência em Libras e uma professora bilíngue ouvinte, fluente em Libras, atuando no que foi nomeado por codocência ou dupla-docência ${ }^{12}$ (Martins \& Lacerda, 2016).

Muitas foram as vezes em que se tentou negociar a mudança dessa forma de educação, prezando pelo retorno da proposta anterior, a qual tinha demonstrado bons resultados. Todavia, o diálogo não aconteceu. A partir disso, optamos pela disseminação das discussões através da produção textual, como forma de resistência, um grito escrito que pede uma escuta para que cresçam programas bilíngues valorizando a Libras na escola. Tal ação é de extrema importância para repensar a educação de surdos e a entrada da língua de sinais, de fato, na instituição (Martins \& Lacerda, 2016, p. 171).

É legítimo conceber, nessa situação, saberes operados por forças que observam a educação proporcionada aos surdos por dois ângulos divergentes. O dualismo poder-resistência

12 Tais propostas novas ainda carecem de pesquisas para observar a efetividade de salas na codocência e a solidificação de ensino bilíngue com a Libras na centralidade das ações educativas. 


\section{pro.posições}

http://dx.doi.org/10.1590/1980-6248-2018-0089

\section{$e$-ISSN 1980-6248}

insinua-se como uma polaridade antagonista, e mesmo axiológica, em que as duas instituições se relacionam em um jogo assegurado por verdades distintas firmadas. É iminente que essas duas instituições - universidade, incorporada pela equipe do projeto inclusivo bilíngue, e Secretaria Municipal de Educação, representada pela nova gestão em exercício no período de 2013 - promoveram um movimento de deslocamento de um saber imposto em detrimento de outro. Porém, para que outra verdade seja implantada, é preciso muita disputa e severas lutas ideológicas. Convém retomar o pensamento de Foucault (2012) citado anteriormente, em que de um lado está o "bastidor", nessa situação fundamentada em pesquisas vinculadas às experiências e estudos das causas surdas, e do outro lado está o "teatro", aqui representado pela gestão pública, voltada para um palco de encenação de uma verdade que se quer simular absoluta, aprofundando discussões que funcionassem como alternativa de aceitação.

Não se tem a intenção de caracterizar órgãos públicos como a representação de um poder que retrata unicamente o Estado, considerando-o essencialmente opressor e designando-o como o foco central de poder, mas como agenciamento de práticas disseminadas nas maquinarias sociais nas quais o poder funciona, e “'ele exclui', ele 'reprime', ele 'recalca', ele 'censura', ele 'abstrai', ele 'mascara', ele 'esconde'. De fato, o poder produz; ele produz atos reais; produz domínios de objetos e rituais de verdade. $\mathrm{O}$ indivíduo e o conhecimento que dele se pode ter se originam nessa produção" (Foucault, 2012, p. 161). Assim, pelas circunstâncias descritas, é possível perceber a instauração de um mecanismo de poder que impõe uma conduta que visa governar as ações resistivas de educação inclusiva bilíngue e faz circular um novo tipo de prática e de verdade, a saber, a abertura de escolas-polo bilíngue em espaços inclusivos. A abertura de salas bilíngues se dá como modificações locais em micromovimentos de mudanças de práticas discursivas de regimes de verdades. É o agenciamento efeito dessas alterações que nomeamos por resistências ou contracondutas, que emergem ao se operar, internamente nas escolas, novas configurações e outros saberes, na medida em que também acionam outras práticas, como o ensino pela Libras, o currículo com conteúdos pensados pela lógica das línguas de sinais, a inserção de profissionais bilíngues, entre outras ações que fazem alterações pequenas nas políticas educacionais em âmbito maior. Os novos saberes insurgentes trouxeram reivindicações e estranhamentos. Queremos dizer que a abertura de salas multisseriadas com instrução em Libras nas escolas municipais não se mantém de modo harmônico. Inúmeras lutas contra o fechamento dessas práticas vêm se produzindo. 


\section{pro.posıções}

http://dx.doi.org/10.1590/1980-6248-2018-0089

Portanto, para que se efetivassem alguns ajustes no programa proposto, foi necessário criar diálogos com a gestão política educacional dos municípios para a promoção de "mudanças de paradigmas, os quais modificam o modo de conceber a surdez dando lugar à emergência da diferença linguística como eixo central para as discussões" (Martins \& Lacerda, 2016, p. 175) vigentes nessa perspectiva educacional de escola-polo. Todavia, sabemos que

esses embates são difíceis de serem travados por se tratarem de uma nova forma de verdade a se firmar, a da diferença, e, com isso, fazer ver a petição surda como dado fulcral para a efetivação de uma escola para surdos - quem mais se não eles mesmos para mostrar quais modelos de escola querem para si? ... Como premissa, a Educação Infantil inclusiva para surdos em uma vertente bilíngue só é possível com a configuração de salas com língua de instrução Libras e com a centralidade da mesma nas ações escolares (Martins \& Lacerda, 2016, p. 175).

Conforme afirmam as autoras, essa nova configuração de escola-polo se fazia necessária principalmente na disposição da Educação Infantil e no Ensino Fundamental I, a qual foi restabelecida de maneira a diminuir as lacunas observadas na implantação de programas aplicados anteriormente e já com resultados de pesquisas assegurando a necessidade de reorganização para as propostas mais atuais, com salas bilíngues que se fizeram multisseriadas pela realidade de cada escola e/ou município. Por meio de experiências advindas do programa em outra instituição escolar, das circunstâncias - aparecendo aqui como um ritual de verdade pode-se perceber a manifestação de um saber outro, fundamentado nas tentativas de acerto, porém percebidos como inconcebível para o ensino de crianças surdas.

Pode-se dizer que os formatos de programa de educação inclusiva bilíngue instaurado em alguns municípios do estado de São Paulo (Piracicaba, Campinas, São Carlos, São Paulo, entre outros) apresentaram-se como uma nova conquista da comunidade surda por meio da parceria de pesquisadores do campo da surdez, como forma de resistência ao modelo inclusivo, especialmente considerando que esse formato de educação é ainda bastante recente e com adequações ainda pouco (re)conhecidas pelos órgãos públicos, o que demanda tempo, conhecimento e exigência constantes (Lacerda, Santos, \& Martins, 2016).

Embora a proposta de programa inclusivo bilíngue para as escolas comuns conte com suas especificações, falhas e avanços, verdades outras vão emergindo em novos discursos, os quais vão se produzindo em campos de lutas entre saberes distintos, procurando se legitimar em diferentes práticas institucionais. Apesar de as "discussões estarem em estágio avançado, embora estas discussões convivam com a resistência de muitos dos responsáveis pela educação 


\section{pro.posıções}

http://dx.doi.org/10.1590/1980-6248-2018-0089

$e$-ISSN 1980-6248

dos municípios, há ainda a necessidade de se implementar ações transformadoras" (Lacerda \& Lodi, 2007, p. 15) para que a realidade educacional dos alunos surdos seja ressignificada e condizente com suas reais necessidades, e que os surdos, de fato, sintam-se inseridos no sistema escolar, segundo suas reivindicações linguísticas, as quais foram aqui partilhadas.

\section{Considerações finais sobre as novas perspectivas bilíngues para surdos: reflexões em aberto}

As tensões apresentadas neste artigo tentaram revelar as lutas para a construção de uma política bilíngue em busca de recursos viáveis que possam garantir a educação que os surdos almejam. Essas lutas devem ser travadas cotidianamente em ações militantes que fraturem de modo micropolítico as verdades postas como imutáveis. Com esse artigo, pretendeu-se estimular provocações para o campo da educação, a fim de incentivar o pensamento em políticas educacionais que têm sido produzidas num campo de batalha entre diferentes saberes que procuraram legitimar as práticas institucionais.

A presença produtiva do poder-saber (sempre presente nas relações sociais) age fortemente na direção de consolidação de formas de vidas, no caso analisado, formas de vidas surdas, sendo ele quem determina a validação dos enunciados presentes em documentos oficiais, assim como foi observado através da perspectiva inclusiva, em que a cada momento se tenta voltar e retomar uma outra educação para os surdos, mesmo eles reivindicando e se posicionando sobre qual escola desejam e querem para si. A produção de verdades legitima modos de vida, e sair de uma prática para outra requer mudanças axiomáticas no que concerne ao valor posto e às práticas normalizadoras impostas para o outro. É assim que, apesar de novas formas de educação de surdos serem ativadas, os valores normativos para o humano (a língua que deve usar a homogeneização de saberes, as construções de padrões normativos e valorativos) ficam evidenciados. Podemos ver o quanto é difícil a consolidação de políticas educacionais que modifiquem a ideologia posta para a inclusão: a saber, a interação entre corpos diferentes em um mesmo espaço, visto que os surdos não pleiteiam a educação inclusiva tal qual é por vezes ofertada como modelo comum. Eles pleiteiam uma escola que fale a língua deles, que faça circular efetivamente a língua de sinais e a pluralidade de vidas surdas. 


\section{pro.posıções}

http://dx.doi.org/10.1590/1980-6248-2018-0089

\section{$e$-ISSN 1980-6248}

No entanto, a reflexão feita mostra que as resistências geram deslocamentos históricos pontuais e formam estes espaços de diferenças surdas que foram destacados. Dessa forma, este trabalho mostrou que é possível ter o movimento de resistência advindo da minoria, mas o tempo todo com o alerta de manter a militância, pois ela é necessária; mostrou ainda as particularidades de determinado programa inclusivo bilíngue direcionado para atuar como alternativa de educação possível para surdos, preocupado em garantir suas determinações linguísticas e a real efetivação dos processos de ensino-aprendizagem escolares desse público. Os eventos sobre os quais aqui se discorreu também procuraram mostrar tensões produzidas por uma política pública educacional que não atendeu e não atende às imperativas demandas linguísticas e culturais necessárias para a qualidade da educação dos surdos no Brasil. Atualmente, tais tensões reverberaram de forma intensa, a ponto de o Exame Nacional do Ensino Médio (Enem) de 2017 trazer o tema da prova de redação abordando os desafios para a formação educacional de surdos no Brasil e ofereceu, ainda, pela primeira vez, a prova na versão em Libras, com 1.897 candidatos surdos que optaram por essa modalidade (Feneis, 2017).

Por essa perspectiva, nota-se que ainda há um saber social que resiste em afirmar sua condição (ideológica) monolíngue, constantemente retomada nos embates do passado vivenciados pelos surdos, e que se continua construindo as políticas de verdade pautadas nesta lógica nos dias atuais. Para Foucault (2012), o problema não é mudar a consciência das pessoas, ou o que elas têm na cabeça, mas o regime político, econômico e institucional de produção da verdade. Por isso, se faz necessário trazer a temática dos surdos no Enem, nos telejornais, nas reuniões em família, nas conversas entre amigos - em todos os espaços - e na problematização científica. O conhecimento precisa ser propagado a todas as pessoas, a fim de que sejam conhecedores de propostas de inclusão das quais os sujeitos surdos façam parte, de modo que eles mesmos possam dizer quais ações os fazem sentir incluídos na sociedade. Sem dúvidas, esse é um desafio de alto grau de dificuldade, pois teria que intensificar o compromisso por uma pedagogia alternativa e assumir a conscientização pela convivência solidária dentro e fora da escola para conseguir trilhar novos caminhos e construir, na diferença, uma escola que parta de uma educação outra, que impacte todas as pessoas e que pratique um currículo pautado na diferença e não na mesmidade. 


\section{pro.posições}

http://dx.doi.org/10.1590/1980-6248-2018-0089

$e$-ISSN 1980-6248

\section{Referências}

Bagno, M. (2008). Preconceito linguístico: o que é, como se faz? (50a ed.). São Paulo: Loyola.

Campello, A. R., \& Rezende, P. L. F. (2014). Em defesa da escola bilíngue para surdos: a história de lutas do movimento surdo brasileiro. Educar em Revista, (2, ed. esp.), 71-92. doi:10.1590/0104-4060.37229

Declaração de Salamanca: sobre princípios, políticas e práticas na área das necessidades educativas especiais. (1994). In Anais da Conferência Mundial de Educação Especial, Salamanca. Recuperado de http://portal.mec.gov.br/seesp/arquivos/pdf/salamanca.pdf

Decreto ${ }^{\circ}$ 3.298, de 20 de dezembro de 1999. (1999, 21 de dezembro). Regulamenta a Lei ${ }^{\circ}$ 7.853, de outubro de 1989, dispões sobre a Política Nacional para Integração da Pessoa Portadora de Deficiência e dá outras providências. Diário Oficial da União, seção 1, 10.

Decreto $\mathrm{n}^{\circ} 5.626$ de 22 de dezembro de 2005. (2005, 23 de dezembro). Regulamenta a Lei $\mathrm{n}^{\circ}$ 10.436, de 24 de abril de 2002, que dispõe sobre a Língua Brasileira de Sinais - Libras, e o art. 18 da Lei no 10.098, de 19 de dezembro de 2000. Diário Oficial da União, seção 1, 28. Recuperado de http://www.planalto.gov.br/ccivil_03/_Ato20042006/2005/Decreto/D5626.htm

Decreto $n^{\circ}$ 6.949, de 25 de agosto de 2009. (2009, 26 de agosto). Promulga a Convenção Internacional sobre os Direitos das Pessoas com Deficiência e seu Protocolo Facultativo, assinados em Nova York, em 30 de março de 2007. Diário Oficial da União, seção $1,3$.

Decreto $\mathrm{n}^{\mathrm{o}}$ 7.611, de 17 de novembro de 2011. (2011, 18 de novembro). Dispõe sobre a educação especial, o atendimento educacional especializado e dá outras providências. Diário Oficial da União, seção 1, 12 . Recuperado de http://www.planalto.gov.br/ccivil_03/_ato2011-2014/2011/decreto/d7611.htm

Federação Nacional de Educação e Integração dos Surdos. (2011). Carta-denúncia dos surdos falantes da Lingua de Sinais Brasileira (Libras) ao Ministério Público Federal sobre a Política de Educação Especial na Perspectiva da Educação Inclusiva imposta à educação de surdos pela Secretaria 


\section{pro.posıções}

http://dx.doi.org/10.1590/1980-6248-2018-0089

\section{$e$-ISSN 1980-6248}

de Educação Continuada, Alfabetização, Diversidade e Inclusão. Recuperado de http://bit.ly/2ROu7go

Federação Nacional de Educação e Integração dos Surdos. (2013). A luta da comunidade surda brasileira pelas escolas bilíngues para surdos no Plano Nacional da Educaşão - PNE. Rio de Janeiro: Autor.

Federação Nacional de Educação e Integração dos Surdos. (2017). Nota à Imprensa: redação do Enem 2017 aborda tema sobre educação para surdos no Brasile abre portas para debate [Postagem de blog]. Recuperado de http://blog.feneis.org.br/nota-a-imprensa-redacao-doenem2017-aborda-tema-sobre-educacao-para-surdos-no-brasil-e-abre-portas-paradebate/

Fernandes, S., \& Moreira, L. C. (2009). Desdobramentos político-pedagógicos do bilinguismo para surdos: reflexões e encaminhamentos. Revista "Educação Especial", 22(34), 225-236.

Foucault, M. (2003). Outros espaços. In M. B. Motta (org.), Estética: literatura e pintura, música e cinema (Ditos \& Escritos, Vol. 3, pp. 411-422). Rio de Janeiro: Forense Universitária.

Foucault, M. (2006). A ordem do discurso. São Paulo: Edições Loyola.

Foucault, M. (2012). Microfísica do poder (25a ed.). Rio de Janeiro: Edições Graal.

Gonçalves, M. L., \& Andrade, A. I. (2007). Disponibilidades e auto-implicação: desenvolvimento profissional e plurilinguismo. Educação, 30(3), 457-477. Recuperado de http://revistaseletronicas.pucrs.br/ojs/index.php/faced/article/view/2743/2090

Lacerda, C. B. F. (2006). A inclusão escolar de alunos surdos: o que dizem alunos, professores e intérpretes sobre esta experiência. Cadernos CEDES, 26(69), 163-184. doi:10.1590/S0101-32622006000200004

Lacerda, C. B. F., \& Lodi, A. C. B. (2007). A difícil tarefa de promover uma inclusão escolar bilíngue para alunos surdos. In Anais da 30ª Reunião Anual da Anped. Recuperado de http://30reuniao.anped.org.br/trabalhos/GT15-2962--Int.pdf

Lacerda, C. B. F, Albres, N. A., \& Drago, S. L. S. (2013). Políticas para uma educação bilíngue e inclusiva a alunos surdos no município de São Paulo. Educação e Pesquisa, 39(1), 65-80. doi:10.1590/S1517-97022013000100005 


\section{pro.posıções}

http://dx.doi.org/10.1590/1980-6248-2018-0089

\section{$e$-ISSN 1980-6248}

Lacerda, C. B. F., Santos, L. F., \& Martins, V. R. O. (Orgs.) (2016). Escola e diferença: caminhos para a educação bilíngue de surdos. São Carlos: EdUFSCar.

Lacerda, C. B. F., Santos, L. F., Lodi, A. C. B., \& Gurgel, T. M. A. (2016). Educação inclusiva bilíngue para alunos surdos: pesquisa e ação em uma rede pública de ensino. In C. B. F. Lacerda et al. (Orgs.), Escola e diferença: caminhos para a educação bilíngue de surdos (p. 13-28). São Carlos: EdUFSCar.

Lodi, A. C. B. (2012). Desenvolvimento de linguagem e apropriação da Libras como primeira língua por crianças surdas e práticas de letramento. In C. R. M. Giroto, S. E. S. O. Martins, \& A. P. Berberian (Orgs.),. Surdez e educaşão inclusiva (pp. 13-35). Marília: Oficina Universitária.

Lodi, A. C. B. (2013). Educação bilíngue para surdos e inclusão segundo a Política Nacional de Educação Especial e o Decreto $\mathrm{n}^{\mathrm{o}}$ 5.626/05. Educação e Pesquisa, 39(1), 49-63. doi:10.1590/S1517-97022013000100004

Lodi, A. C. B., \& Lacerda, C. B. F. (Orgs.). (2009). Uma escola duas linguas: letramento em lingua portuguesa e língua de sinais nas etapas iniciais de escolarização. Porto Alegre: Mediação.

Lopes, M. C. (2007). Surdez \& educação. Belo Horizonte: Autêntica.

Martins, V. R. O. (2016). Tradutor e intérprete de língua de sinais educacional: desafios da formação. Belas Infiéis, 5(1), 147-163.

Martins, V. R. O., \& Lacerda, C. B. F. (2016). Educação inclusiva bilíngue para surdos: problematizações acerca das políticas educacionais e linguísticas. Revista de Educação, 21(2), 163-178. doi:10.24220/2318-0870v21n2a3277

Mendes, E. G. (2006). A radicalização do debate sobre inclusão escolar no Brasil. Revista Brasileira de Educação, 11(33), 387-405. doi:10.1590/S1413-24782006000300002

Morais, M. P. (2018). Trajetórias de resistência em escolas municipais com propostas de educação bilingue inclusiva para surdos. Dissertação de Mestrado, Universidade Federal de São Carlos, São Carlos.

Mourão, C. H. N. (2011). Educação de Surdos: retrocedendo para Milão: será? In $4^{0}$ Seminário Brasileiro de Estudos Culturais e Educação e $1^{\circ}$ Seminário Internacional de Estudos Culturais e Educação (pp 1-12), Universidade Luterana do Brasil, Canoas. 


\section{pro.posıções}

http://dx.doi.org/10.1590/1980-6248-2018-0089

$e$-ISSN 1980-6248

Müller, J. I., Sturmer, I. E., Karnopp, L. B., \& Thoma, A. S. (2013). Educação bilíngue para surdos: interlocução entre políticas linguísticas e educacionais. Nonada: Letras em Revista, 2(21), 1-15.

Perlin, G. (1998). Identidades surdas. In C. Skliar (Org.), A Surde飞: um olhar sobre as diferenças (pp. 51-73). Porto Alegre: Editora Mediação.

Plano Nacional de Educaşão 2014-2024. (2014). Lei no 13.005, de 25 de junho de 2014, que aprova o Plano Nacional de Educação (PNE) e dá outras providências (Série Legislação, Num. 125). Brasília, DF: Edições Câmara.

Portaria n 1.060, de 30 de outubro de 2013. (2013, 31 de outubro). Institui Grupo de Trabalho com o objetivo de elaborar subsídios para a Política Nacional de Educação Bilíngue Língua Brasileira de Sinais e Língua Portuguesa .... Diário Oficial da União, seção 1(212), 44. Recuperado de http://bit.ly/36I9G91

Portaria $n^{\circ}$ 1.679, de 2 de dezembro de 1999. (1999, 3 de dezembro). Dispõe sobre requisitos de acessibilidade de pessoas portadoras de deficiências. Diário Oficial da União, seção 1, 215. Recuperado de http://portal.mec.gov.br/sesu/arquivos/pdf/c1_1679.pdf

Silva, M. L. F. S., Fernandes, E. A. P., \& Rocha, D. S. (2016). IV Setembro Azul: um cenário de lutas e reflexões. In H. A. M. Lins, R. M. Souza, \& L. C. R. Nascimento (Orgs.), Plano nacional de educação e as politicas locais para implantação da educação bilíngue para surdos (Série Setembro Azul, Num. 4, pp. 55-64). Campinas: Unicamp.

Skliar, C. (1998). A surdeæ: um olhar sobre as diferenças. Porto Alegre: Mediação.

Slomski, V. G. (2012). Educação bilíngue para surdos: concep̧̧ões e implicações práticas. Curitiba: Juruá.

\section{Referências consultadas}

Deleuze, G., \& Guattari, F. (2014). Kafka: por uma literatura menor. Belo Horizonte: Autêntica.

Federação Nacional de Educação e Integração dos Surdos. (2011). Nota sobre a Internacional Disability Alliance - IDA. Rio de Janeiro: Autor.

Grupo de Trabalho da Política Nacional de Educação Especial. (2008). Política Nacional de Educação Especial na Perspectiva da Educação Inclusiva. Brasília, DF: MEC/SEESP. 
Martins, V. R. O. (2008). Educaşão de surdos no paradoxo da inclusão com intérprete de língua de sinais: Relações de poder e (re)criações do sujeito. Dissertação de Mestrado, Universidade Estadual de Campinas, Campinas.

Submetido à avaliação em 13 de agosto de 2018; revisado em 21 de dezembro de 2018; aceito para publicação em 27 de abril de 2019. 